\title{
Diversidade, Agendas de Cultura e Desenvolvimento e Mediações no Campo de Poder Global'
}

\author{
Edson Farias ${ }^{2}$
}

Artur André Lins ${ }^{3}$

Resumo: A dinâmica de mundialização da ideia de cultura constitui o pano de fundo deste artigo. $\mathrm{O}$ emprego da abordagem figurativo-processual toma por objeto de conhecimento as mediações cujos efeitos tecem as agendas de cultura e desenvolvimento como figuras sociais em que a narrativa da diversidade cultural e a teoria do capital humano se engendram mutuamente, forjando um mecanismo contemporâneo de coordenação de relações sociais. O interesse que move o texto é esclarecer a posição ocupada por esse mecanismo no posicionamento do dueto Estado e mercado no campo de poder global.

Palavras-chaves: Diversidade Cultural; Agendas de Cultura e Desenvolvimento; Mediações; Campo de Poder Global.

\section{Cultural Diversity, Cultural and Developmental Agendas and Mediations in Global Field of Power}

\footnotetext{
1 Uma versão preliminar deste texto foi apresentada durante o Seminário "Práticas Culturais Contemporâneas" - no Centro de Pesquisa e Formação do SESC, 22/23 de outubro, São Paulo, 2015.

2 Departamento de Sociologia - Universidade de Brasilia (UnB) - Pesquisador do CNPq/ pesquisador CMD/UnB - Brasília - Brasil - nilos@uol.com.br.

3 Graduando em ciências sociais - Universidade de Brasilia (UnB) - Brasília - Brasil - aalins@hotmail.com.
} 
Abstract: The dynamics of the mundialization of the idea of culture is the backdrop for this paper. The adoption of figurational-process sociology assumes mediations as an object of knowledge whose effects weave the cultural and developmental agendas into social figures in which the accounts of the cultural diversity and the human capital theory engender each other forging a contemporary mechanism for coordination of social relations. The driving concern in the text is clarifying the position occupied by this very mechanism in the setting out of the State-market duet within the global field of power.

Keywords: Cultural Diversity; Cultural and Developmental Agendas; Mediations; Global Field of Power

Escudados no trajeto da pesquisa e reflexão sobre processos estatais, realizado entre 2010 e 2013, ${ }^{4}$ neste artigo, ao esboçarmos o delineamento cartográfico do cruzamento funcional entre os órgãos federais de cultura, no Brasil, em algumas das suas interfaces com outras instâncias do mesmo Estado nacional, ${ }^{5}$ na última década, importa equacionar a posição ocupada pelas agendas de cultura e desenvolvimento executadas nessas instituições, mas à luz dos desdobramentos dos dois seguintes argumentos. Por um lado, a premissa sobre a transversalidade da questão cultural, no instante em que esta é concebida como um recurso no qual contracenam instâncias e agenciamentos entretidos no campo de poder global. De outro, identificadas como dispositivos discursivos e institucionais plasmados nesse espaço de poder, estamos convencidos de que as agendas de desenvolvimento ajudam a elucidar os meios pelos quais saberes e fazeres, ao lado de patrimônios artísticos e culturais, são vertidos em alavancas sustentáveis de desenvolvimento local, promovendo a metamorfose desses elementos e, por consequência, os seus agentes, em capitais humanos catalisados em circuitos comerciais translocais de bens da etnicidade e da diferença. Em última instância,

4 Referimo-nos à pesquisa Agendas de Cultura e Desenvolvimento: Figuração da regulação estatal das diferenças sociossimbólicas, desenvolvida (2011-2014) com apoio do CNPq, na modalidade bolsa de produtividade em pesquisa. Foram imprescindíveis, nesse percurso, o auxílio e as contribuições dos bolsistas de iniciação científica ProIC/UnB-CNPq Thais Rocha (2011-2012), Lucas Marquês (2011-2012), Quelian Silva (2011-2012), Artur Guimarães (2012-2013) e Lucas Facó (2012-2013).

5 Os procedimentos (envolvendo observação participante, realização de entrevistas de profundidades com técnicos e dirigentes, mais pesquisa documental) foram adotados na estadia nos seguintes órgãos: Ministério da Cultura, Instituto do Patrimônio Histórico e Artístico Nacional (IPHAN) e Fundação Palmares. Ainda, na Secretaria Nacional da Identidade e da Diversidade Cultural (SNIDC). Mas, também, na Secretaria Especial de Políticas de Promoção da Igualdade Racial (SEPPIR), no Instituto Nacional de Colonização e Reforma Agrária (INCRA) e nos Ministérios do Desenvolvimento Social e da Justiça. 
a reflexão problematiza a natureza da coordenação das relações sociais derivada dessa disposição de bens e práticas culturais no enlaçamento mútuo entre Estado e mercados autorregulados, cujos limites vazam as fronteiras nacionais.

Três momentos compõem o itinerário expositivo e analítico do artigo, o qual obedece ao critério processual de atentar às interdependências funcionais que vão se estabelecendo e delineando as identidades dos termos que compõem a dinâmica sócio-histórica, na qual as agendas de cultura e desenvolvimento se inscrevem. De início, com o intuito de sinalizar a alteração recente no vínculo histórico na relação entre Estado e cultura no Brasil, esse debate será revisitado de modo sumário. A finalidade é cercar as linhas gerais dos condicionantes que ora organizam as convergências entre o ordenamento estatal de poder e os âmbitos de significados e identidades sociais no país. A ênfase estará depositada no lugar ocupado pela fala sobre as diversidades culturais na aproximação entre as lógicas culturalista e instrumental no quadro da razão estatal brasileira, a nosso ver, sintetizada no advento das agendas de cultura e desenvolvimento. Na sequência, a atenção às mesmas agendas consistirá no ponto de partida para observarmos algumas mediações que deixam no seu rastro a ingerência da narrativa da diversidade como elemento simbólico, discursivo e normativo capaz de soldar diferentes posições internas ao campo de poder global. O texto é encerrado levando em conta o papel estratégico dessas agendas no que toca ao entrecruzamento dos fatores de gerenciamento e de governança na qualificação das práticas culturais e seus agentes no perfil de capital humano.

\section{Outro estágio na relação Estado e cultura?}

O livro Memória e Patrimônio: ensaios contemporâneos é ilustrativo de remanejamentos sensíveis na relação entre Estado e cultura no Brasil, em ocorrência nas últimas décadas. Editada em 2003, a coletânea, que reúne textos de antropólogos, historiadores, sociólogos - entre os quais alguns lotados em órgãos estatais voltados ao tema da cultura, como o Instituto do Patrimônio Histórico Artístico Nacional (IPHAN) -, é contemporânea do momento em que a questão do patrimônio imaterial fazia eco nas políticas culturais no país, acompanhando uma tendência internacional. Na obra se evidencia espécie de redescoberta do problema em torno da memória social, em meio às inflexões pós-modernistas e desconstrutivistas ${ }^{6}$ estendidas à nação com suas prerrogativas originárias de homogeneizar segundo o marco da identidade e da cultura nacionais.

6 Em lugar de enfatizar a nação como uma ideologia ou mesmo um sistema cultural que determina os desempenhos, intérpretes vinculados aos chamados estudos pós-coloniais passaram a tomá-la como 
De algum modo, o livro fazia evocar a proposição, propalada desde a década de 1990, de que, em lugar do Estado-nação, ganhava vulto o "Estado-nações", na medida em que a diversidade étnico-cultural se imporia, inclusive no delineamento republicano do Estado democrático de direito (Cavalcanti, 1999: 33). Assinado pelos dois organizadores, o texto da "Introdução" identifica, no empenho conjunto de intelectuais e segmentos detentores de saberes tradicionais e locais da sociedade nacional, uma silenciosa revolução cujo desfecho atingiria em cheio a monofonia da narrativa épica da nação, no momento em que altera a concepção de patrimônio cultural pela tônica posta na intangibilidade. Ambos os autores acentuam que se desprenderiam dessa mediação polifônica de experiências outras de colecionamento, deixando patente a emergência do "exercício ao direito de voz" por parte de grupos que "tradicionalmente" teriam ocupado o "lugar de alteridades nas grandes narrativas nacionais". (Abreu; Chagas, 2003: 13). Tais práticas museológicas e museográficas seriam a contrapartida de...

(...) narrativas urbanas, regionais e locais nas quais está em jogo a construção de uma identidade específica, capaz de articular outras tantas narrativas, em função de um eixo arbitrariamente construído. Esse eixo ordenador quer também exercer um papel na mediação em relação ao local, nacional e global (Abreu; Chagas, 2003:13).

Investidas com igual perfil, as premissas do direito e da afirmação cultural parecem encontrar respaldo nos dispositivos de políticas públicas que são acionados no âmbito federal do ordenamento público. Elaborado e votado mais tarde, em 2011, pelo Congresso Nacional, o Plano Nacional de Cultura (PNC) estabelece as metas a serem alcançadas até 2020, tendo por objetivo promover extensiva e democraticamente os direitos culturais. No texto de apresentação do PNC, a então ministra da Cultura Ana de Hollanda destaca, exatamente, na maior participação social, um dos fundamentos do documento:

O PNC foi escrito por milhares de mãos, por meio de diferentes instâncias e espaços de experimentação e participação. Um plano que reflete o esforço coletivo para assegurar o total exercício dos direitos culturais dos brasileiros e das brasileiras de todas as situações econômicas, localizações, origens étnicas e faixas etárias. 
Adicionado aos argumentos desenvolvidos por Abreu e Chagas, este trecho nos deixa diante de duas perguntas, a nosso ver, relacionadas entre si. De um lado, do ponto de vista institucional, em que se lastreia o "direito à voz" dessa polifonia? Sendo o Estado nacional o que proporciona o arcabouço jurídico-institucional de tal direito, ${ }^{7}$ como se dá a congruência entre a prerrogativa de imputação do sentido legítimo por parte do ordenamento público estatal e a evocação de autonomia relativa dessas vozes múltiplas, circulando igualmente distintas narrativas?

Na proposição de Abreu e Chagas, vimos, a polifonia das vozes consistiria numa mediação apta a aproximar os tantos e diferenciados componentes culturais, forjando uma identidade capaz de representar toda essa diversidade. Logo, no instante em que se reveste da autoridade de uma metaenunciação, urdida mediante a articulação promovida entre as diferenças culturais, a própria diversidade se converte num demiurgo narrativo que textualiza, ao apresentar os objetos a que se refere e ao posicionar os sujeitos que o enunciam. Torna-se hábil, portanto, na tradução dos díspares, porém, sem que a solda que ela realiza dissolva as singularidades (ver Oliveria, 2004; Vianna, 2003; Velho, 2006; Carvalho, 2006). Por sua vez, o pronunciamento de Ana de Holanda se antecipa na descrição da acomodação da cultura à razão estatal na medida mesma em que, uma vez mais, a diversidade é destacada na mediação realizada entre as muitas diferenças socioculturais, incluindo também o próprio Estado, durante a escrita do PNC (Reis, 2011:129-154).

Deixaremos para adiante problematizar a mediação exercida pelas séries de enunciados em torno da diversidade porque salta à vista como os dois pontos de vista apresentados revelam um deslize no entendimento das relações entre Estado e cultura no Brasil. Se tomarmos por paradigmático o evento político-institucional de 1930 e, na sua contrapartida, tanto o incremento do binômio composto por urbanização e industrialização, quanto o protagonismo da visão modernista empenhada na redescoberta do Brasil, com vista a erguer uma sociedade nacional moderna e original, mesmo em que pesem as nuances históricas, na sucessão de episódios abarcando, além da fase da ditadura varguista, o período da república populista, os governos militares até o período da redemocratização, na metade final dos anos 1980, a postura do ordenamento estatal

7 A constituição federal em vigor, desde 1988, no artigo 215 declara: "O Estado garantirá a todos o plexo exercício dos direitos culturais e acesso às fontes da cultura nacional, e apoiará e incentivará a valorização e a difusão das manifestações culturais.. 
frente à sociedade, pela mediação da questão cultural, estará pautada pela tônica da unidade ideológica da nação (Oliven, 2002: 13-43).

No andamento da centralidade adquirida pela unidade nacional, ao se entronar como fiador e guardião por excelência da identidade pátria, no arranjo entre facções intelectuais e elites políticas, o coágulo de relações de forças sociais aninhado no Estado central, desde o mesmo episódio de 1930, não somente se reconhece legislador da demarcação do "próprio" e "alheio" ao seio da cultura brasileira, como, também, legisla sobre os limites entre os níveis culturais e do que lhe é, respectivamente, pertinente no que concerne aos símbolos, costumes e expressões. Quando atribui outro significado à tematização do nacional-popular no país, Renato Ortiz (1984) fornece uma síntese acerca do encadeamento entre Estado, cultura e sociedade no Brasil de acordo com a sintonia estabelecida entre cultura e identidade nacionais.

O autor retoma o problema segundo a base canônica do conceito de nacional-popular, assim, atualizando o raciocínio gramsciano a respeito da construção de uma hegemonia na sociedade, exercida pela ação dos grupos dominantes (detentores do excedente material e simbólico). Inserida no Estado, infere Ortiz, a fração intelectual desses grupos tornou-se arquiteta e construtora de um edifício cultural comum, a partir do qual se passou à constituição da consciência nacional. E, nesse processo, a heterogeneidade fragmentada do popular concorreu como matéria-prima crucial carreada à elaboração da alquimia ideológica cuja eficácia reside em transformar o disperso material das expressões das classes populares em representantes de um mesmo espírito nacional-popular.

Desse modo, afirma o autor, a problemática em torno da particularidade do popular, quando confrontada com a universalidade de uma memória nacional, no contexto da sociedade brasileira, foi resolvida pela compreensão da constante reelaboração discursiva do traço mestiço feito intrínseco à "cultura do povo. Logo, a heterogeneidade nela evidenciada pela presença de resquícios indígenas, negros e brancos torna-se, na trilha do pensamento de Gilberto Freyre, sinônimo de uma identidade plural, mas distinta de qualquer outra ao ser igual a si mesma (Ortiz, 1984: 138).

Em termos dos efeitos obtidos por uma sistematização institucional mais abrangente, a pressão legislativa por parte do Estado nacional sobre os modos de simbolização cultural irá ganhar maior fôlego no período da ditadura militar. Como adverte Sérgio Miceli (1984), até aquele momento inexistia uma política cultural oficial, afinal faltava linha de comando centralizado, metas definidas e aferição de resultados, exatamente na contramão do que já ocorria na área econômica. De acordo, ainda, com o autor, a passagem de 
Ney Braga pelo Ministério da Educação, entre os anos de 1974 e 1978, marcou esse divisor de águas no momento em que asseverou a implantação da Política Nacional de Cultura - primeiro plano oficial movido pelo propósito de tornar a presença governamental ampla na área cultural. Conclui Miceli que fora essa a primeira vez, na história republicana, em que o governo formalizou um conjunto de diretrizes para orientar suas atividades na área cultural (Calabre, 2006:81-98; Botelho, 2001).

A conclusão se aproxima do diagnóstico de Gabriel Cohn (1984). Ele entende que, partir da década de 1970, paulatinamente se sistematiza uma política nacional federal com a finalidade de codificar e controlar o processo cultural. Portanto, a fase derradeira da ditadura pavimentou o caminho institucional que culminou com a criação do Ministério da Cultura, em 1985, já no início do processo de redemocratização do país. Ainda segundo Cohn, é, diante da relativa assonância cultural da esquerda no país, que o regime ditatorial respondeu à necessidade de formular uma política cultural própria. Nessa agenda, $\mathrm{o}$ ponto fundamental estava na formação de uma personalidade nacional forte $\mathrm{e}$ influente, isto ao se acreditar que, desenvolvendo a temática do cultural e do popular, o governo se colocaria à dianteira da construção de uma nova sociedade. A cultura, assim, constituía um subsídio irrefutável à formação e identificação da personalidade nacional, porque seria “(...) sua expressão mais alta, e sua defesa impõe-se tanto quanto a do território, dos céus e dos mares pátrios” (Cohn, 1984: 90). É nesses termos que, uma vez mais, propõe Ruben Oliven (1984: 51), o Estado se transforma no "criador e bastião da identidade nacional", manipulando os símbolos nacionais no esforço de montar uma hegemonia.

Nota-se que, à luz desse sumário histórico apresentado, a fase definida pelo retorno gradual do país ao Estado democrático de direito, na metade finm dos anos de 1970, guarda certa ambiguidade no tocante à correlação entre Estado e cultura. Se houve um reforço enorme da intervenção estatal nos âmbitos de produção, circulação e consumo de bens simbólicos, o período derradeiro do domínio ditatorial militar comportou uma virada na relação Estado e cultura, do ponto de vista institucional, estendida do chamado período da distensão política, atravessando a eleição indireta de um governo civil, passando pela instauração da Assembleia Constituinte, a qual vota o novo texto constitucional em 1988, tendo por desfecho a eleição de um presidente escolhido por voto popular. Isto, na medida em que é o terreno preparado à introdução, entre as obrigações estatais, de velar pelo direito à cultura dos cidadãos brasileiros, na sua dupla face de acesso aos bens culturais e de pertencimento, respectivo, a culturas específicas. 
Suspeitamos que, desde esse momento, a dinâmica sócio-histórica que conduz à implantação do direito à cidadania cultural, no Brasil, tem-se reverberado em alterações funcionais estatais, particularmente, a função de imputação do sentido legítimo. Quer dizer, o direito à cidadania cultural, para se realizar, pressiona vários planos do ordenamento estatal público, pois requer crescentes esforços para equalizar demandas diversas de reconhecimento e juridificação de identidades coletivas e distribuição das diretrizes de soberania da máquina estatal (Arruti, 2005). Mas, por isso mesmo, por outro lado, parece-nos que, de modo simultâneo, a mesma normatividade em torno do direito cultural se insere como dispositivo entre os mecanismos de regulação populacional e coordenação social, ao fomentar a valoração dos elementos psíquicos (proposições identitárias) e as habilidades (saberes e fazeres) como recursos.

Deixemos para adiante os desdobramentos desse argumento. Por enquanto, daremos continuidade à exposição do cenário institucional no qual o Estado nacional incide sobre a questão cultural na perspectiva do arranjo promovido entre a diversidade cultural e a sustentabilidade. Para isso, retomamos os dados empíricos resultantes da nossa pesquisa, em que focalizamos o período dos oito anos da administração federal Lula da Silva.

Muito ilustrativa a respeito é a conceituação inerente à montagem do Sistema Nacional do Patrimônio Cultural (SNPC), a qual se impôs como prioridade na pauta do IPHAN, durante a segunda metade da década passada (Oliveira, 2008). Aqui não iremos nos ater às dificuldades e celeumas envolvendo conflitos interpretativos em torno dos marcos doutrinários deflagrados entre pontos de vistas relativos a distintas posições, seja no próprio órgão, seja no Ministério da Cultura e, ainda, em outros setores do governo. ${ }^{8}$ Importa-nos somente identificar os princípios advogados como chave à gestão do patrimônio cultural brasileiro (Sant'Anna, 1990; Gonçalves, 1996; Nogueira, 2007). Não é demais lembrar que, implantado em 2007 , de acordo com a justificativa fornecida pelo IPHAN, o SNPC responde ao desafio de estabelecer relações intragovernamentais cujo desfecho fomente diálogos e, assim, viabilize ações articuladas nacionalmente de gestão do patrimônio cultural. De acordo com o grupo de trabalho instalado para pensar o patrimônio cultural brasileiro, órgão consultor e parte do "Fórum Nacional do Patrimônio Cultural Brasileiro", os objetivos persegui-

8 Os desencontros entre interesses e perspectivas no interior do sistema MinC colocam, muitas das vezes, em posições opostas facções com tendências mais mercadológicas e outras defensoras da dimensão simbólica do patrimônio. Exemplar são as disputas em torno do artesanato e de outros patrimônios intangíveis, atualmente, envolvendo interesses no IPHAN frente aos defendidos pela então recém-criada Secretaria da Economia Criativa, a esse respeito consultar Marquês (2012: 11-16). 
dos no SNPC se relacionam à reciprocidade entre os três seguintes eixos: coordenação, regulação e fomento.

Já como consequência da proposta de interlocução e articulação intragovernamental, em sintonia com a Casa Civil da Presidência da República, estabeleceu-se o Programa de Aceleração do Crescimento voltado às Cidades Histórias (PAC-Cidades Históricas). A finalidade desse programa é, em conjunto com setores da sociedade civil, preservar o patrimônio brasileiro, valorizar as culturas locais ou regionais e, a partir dessas, a cultura brasileira. E, ainda, promover o desenvolvimento econômico e social com sustentabilidade, assegurando a qualidade de vida aos moradores das localidades. Assim, articulando os ministérios do Turismo, da Educação e das Cidades, além da Petrobras, do BNDES, mas também a Caixa Econômica e o Banco do Nordeste, o PAC-Cidades Históricas se propõe a ampliar as políticas patrimoniais para as várias cidades históricas brasileiras, incluindo a parceria com o Banco Interamericano de Desenvolvimento (BID) e o braço da Organização das Nações Unidas para Educação e Cultura (UNESCO), manifestado no programa "Monumenta" (Werthein, 2002: 136-137;153-157). ${ }^{9}$

A contrapartida na execução do PAC-Cidades Históricas está no conceito de "educação patrimonial". Este projeto pedagógico tem por objetivo disseminar um conhecimento a respeito do valor patrimonial dos bens entre as respectivas populações, incluindo grupos de cultura popular, artistas e demais habitantes dessas cidades e tornar o patrimônio um bem simbiótico aos respectivos mundos fenomenológicos e afetivos comunitários. Desse modo, ainda permanece postado no sítio na Internet do IPHAN:

O patrimônio cultural é o conjunto de manifestações, realizações e representações de um povo, de uma comunidade. Ele está presente em todos os lugares e atividades: nas ruas, em nossas casas, em nossas danças e músicas, nas artes, nos museus e escolas, igrejas e praças. Nos nossos modos de fazer, criar e trabalhar. Nos livros que escrevemos, na poesia que declamamos, nas

9 O "Monumenta" tem por coordenadoria o IPHAN e se volta aos centros históricos de cidades sob a guarda da instituição, com o objetivo de assegurar a sustentabilidade financeira do patrimônio cultural (Taddei Neto, 2003: 105-116). Para isso, a proposta visa conjugar interesses turísticos e educacionais. O programa opera mediante convênios firmados entre o MinC e as prefeituras/estados. Até agora 26 cidades estão integradas ao programa: Alcântara (MA), Belém (PA), Cachoeira (BA), Congonhas (MG), Corumbá (MS), Diamantina (MG), Goiás (GO), Icó (CE), Laranjeiras (SE), Lençóis (BA), Manaus (AM), Mariana (MG), Natividade (TO), Oeiras (PI), Olinda (PE), Ouro Preto (MG), Pelotas (RS), Penedo (AL), Porto Alegre (RS), Recife (PE), Rio de Janeiro (RJ), Salvador (BA), São Cristóvão (SE), São Francisco do Sul (SC), São Paulo (SP), Serro (MG). 
brincadeiras que organizamos, nos cultos que professamos. Ele faz parte de nosso cotidiano e estabelece as identidades que determinam os valores que defendemos. É ele que nos faz ser o que somos. Quanto mais o país cresce e se educa, mais cresce e se diversifica o patrimônio cultural. 0 patrimônio cultural de cada comunidade é importante na formação da identidade de todos nós, brasileiros.

$\mathrm{Na}$ análise dos documentos referentes aos PNC e o PAC-Cidades Históricas, se evidenciam tentativas no sentido de efetivar conexões entre identidades, comunidades, patrimônio, valores culturais e sustentabilidade. No período focado na pesquisa, essa diretriz estatal estava direta ou indiretamente presente na execução de vários outros projetos e programas voltados para a questão cultural. Conexões, por sua vez, referenciadas pela interpelação do ordenamento estatal, no instante em que este se apresentava como mediador e avalista da singularidade étnico-histórica e afetiva das diferentes comunidades atendidas. Mas, ao mesmo tempo, quando tonificava e perseverava a favor da autossustentação do patrimônio cultural e, por esse viés, evocava a sustentabilidade dos legatários dos saberes e fazeres classificados como patrimônio intangível ou imaterial, os enunciados que partiam do órgão estatal reclamavam o reconhecimento da cultura como fator apto a gerar riqueza e renda. E, no anverso, identificava, nesses saberes/fazeres, recursos coletivos realizados pelos distintos membros de uma comunidade. Com isso, entendia esses fatores como alvos a serem potencializados mediante a ação dos instrumentos do Estado com ou sem a colaboração da iniciativa privada empresarial ou do terceiro setor, por meio da execução de políticas públicas.

Durante entrevista concedida em 2010, o então ministro da cultura Juca Ferreira alardeia a concepção de desenvolvimento humano em que a simbolização é parte inalienável da condição da espécie. Por essa perspectiva, ele ressalta o que entende ser uma reviravolta profunda na compreensão da nação brasileira, porque a complexidade cultural do país estaria sendo reconhecida como parte de um "projeto multidimensional" de desenvolvimento. Uma faceta do projeto estava, justamente, em integrar, ao cômputo da riqueza nacional, a economia relativa à diversidade sociocultural do Brasil, para além dos âmbitos artísticos identificados aos circuitos jurídicos formais (Almeida; Albernaz; Cerqueira, 2013: 212-213). A fala do ministro se mostra sintética e elucidativa, a um só tempo. Apreendida por sua transversalidade, a cultura ocupa lugar estratégico no projeto de desenvolvimento totalizador cujos braços alcançam, pondo-os em reciprocidade, os planos simbólicos e identitários com aquele da instrumentalidade 
afim ao atendimento das carências sócio-humanas. O que se elucida é como a mesma transversalidade reveste a cultura do status de assegurar uma pauta de prioridades que se antecipa e, de modo simultâneo, atravessa as práticas do poder público estatal, dando-lhes unidade por lhes conferir diretriz.

Desse modo, o arranjo dessas práticas se constitui numa agenda definida pelo entrosamento mútuo de cultura e desenvolvimento. A síntese diz respeito à compilação de ideias nele contidas. A fala denuncia a longa continuidade de um comando colonial, que teria subjugado as partes majoritárias das matrizes culturais e grupos sócio-humanos que compõem a nação brasileira. Reclama, igualmente, dessa mesma linha de força por impor um modelo desenvolvimentista incapaz de potencializar esses elementos socioculturais do país, segundo o objetivo de equacionar uma economia, de um lado, descompromissada com a exportação de bens primários com poucos valores agregados; de outro, sintonizada com o estágio contemporâneo no qual a trama complexa da cultura constitui um setor de ponta na remuneração do capital, logo, decisivo na geração de valores financeiro-monetários e de alocação de trabalhos.

Os interesses que contracenam com a retórica política justificam o teor voluntarista do pronunciamento do ministro. Não se trata de negar a importância das medidas tomadas durante o período da administração Lula da Silva (Rubim, 2008). Contudo, um olhar retrospectivo relativiza o esforço de Juca Ferreira em assegurar o protagonismo de terem instituído a guinada da cultura no Brasil aos seus atos e do quadro político-partidário em que se inscreve, aliando-a ao tema do desenvolvimento socioeconômico. A posição que ele ocupou no alto comando da República, ela mesma detém uma memória de presenças e mediações que se revelaram cruciais, tanto ao status conferido à cultura, quanto à revisão na concepção de desenvolvimento.

\section{Vozes culturais do desenvolvimento}

Consignatário das Convenções do Patrimônio Mundial (1972), do Patrimônio Imaterial (2003) e da Diversidade das Expressões Culturais (2005), o Brasil tem se destacado entre os membros da Unesco quando o tema envolve as componentes bióticas e étnico-históricas, agora tomadas por signos da "riqueza" do planeta e da humanidade (Evangelista, 2003). Para alguns intérpretes, tal ativismo brasileiro seria a contrapartida da existência no território nacional de patrimônios que se estenderiam do Parque Natural das Cataratas do Iguaçu ao conjunto arquitetônico-urbanístico de Brasília. Outros, sem desconsiderar essa perspectiva, chamam a atenção para o fato de que o acelerado desenvolvimento 
socioeconômico conhecido pelo país, ao longo do Século XX, trouxe o risco de dano e mesmo extinção de toda essa mesma diversidade. O segundo ponto de vista nos parece especialmente heurístico aos propósitos deste artigo pelos dois motivos a seguir explanados.

O primeiro aspecto corresponde ao fato de que o estabelecimento da correlação entre desenvolvimento e cultura está bem mais enraizado em certo imaginário acerca da história do país, especialmente no momento em que os efeitos da tecnificação da produção sob o protocolo do produtivismo capitalista se torna alvo de interesse crítico. Inflexão esta que se deu na passagem dos anos de 1970 para os anos 1980, quando, em meio ao declínio e estagnação das taxas de crescimento econômico, o primeiro grande ciclo da dinâmica urbano-industrial no país se encerrou. Foram vozes identificadas ao círculo ideológico das esquerdas políticas, aquelas que, ao fazerem o balanço do hercúleo esforço nacional em se industrializar com vistas a furar o teto do subdesenvolvimento, detectaram desvios e dilacerações na execução de um projeto de modernização entendido depreciativamente como dependente, colonial, tão somente movido pelo ímpeto mimético de repetir, aqui, o empenho de ativar as forças produtivas, portanto, sendo cego obediente à narrativa teleológica do progresso.

Desse modo, entre os reclamos de fundo existencialista acerca da insolvência da identidade nacional, no instante em que estaria incapacitada de ser, isto porque impedida de se autoperceber, discernindo o que lhe seria autêntico, pronunciamentos hastearam a bandeira do quanto se fazia crucial mover-se na direção do conúbio entre cultura e desenvolvimento. Como sintetiza o economista Celso Furtado:

No centro das indagações que aqui nos reúne está a interação da cultura como sistema de valores com o processo de desenvolvimento das forças produtivas, a interface entre a lógica dos fins, que rege a cultura, e a dos meios, razão instrumental inerente ao desenvolvimento da capacidade produtiva (Furtado, 2012: 40).

O posicionamento de Furtado parece amparar, no tocante ao plano histórico das práticas dos agentes envolvidos, a consideração de Gabriel sobre o temor do governo ditatorial militar no Brasil diante do avanço de segmentos de esquerda na área cultural, antes apresentada. Enuncia Celso Furtado a assertiva de que a última fase daquele regime enfrentou a crescente assonância das facções intelectuais de esquerda, que incitavam a desqualificação do estado de exceção autoritário instalado em 1964, pela denúncia do modelo de desenvolvimento 
adotado com sua feição, tanto concentracionista de renda e de bens de produção, quanto pelo furor de esgotar os recursos naturais e desumanizar a sociedade.

Assim, a mesma tomada de posição por parte de Furtado nos leva a um segundo aspecto a ser descrito: a atribuição de status à questão cultural como fator relevante política e socioeconomicamente. Vale recordar que o trecho transcrito faz parte da conferência proferida pelo economista durante o I Encontro Nacional de Política Cultural, realizado em Belo Horizonte, em abril de 1984. Ou seja, o país já aspirava àquela atmosfera de redemocratização, anunciando o término do período da ditadura sob os ecos do movimento popular das "Diretas Já". E, na mesma medida, teciam-se os acordos políticos que dariam suporte à nova arquitetura institucional, posteriormente denominada "Nova República". Não deixa de ser curioso que a voz de Celso Furtado, nacional e internacionalmente respeitada por sua atuação histórica na Comissão Econômica para a América Latina e o Caribe (CEPAL) no sentido de superar o subdesenvolvimento dessas regiões do Planeta, levante-se para refutar o modelo desenvolvimentista do qual, de alguma maneira, ele fora um dos mentores intelectuais (Mallorquin, 2012: 153-179). Na denúncia, ele recorre à evocação um tanto utópica da aliança entre cultura e economia. Mais ainda. Chama a atenção o fato de um evento sobre políticas culturais ocupar posição estratégica na manifestação de posicionamentos político-ideológicos que teriam sensível impacto sobre a virada institucional que o país vivia, mas também se desdobraria na consolidação desse novo estágio político-institucional da República brasileira. Não é demais recordar que, no primeiro governo desse estágio, a administração José Sarney, cria-se o Ministério da Cultura, e o mesmo Furtado será o segundo titular da pasta, entre 1986 e 1988.

Destaca-se a posição de mediador exercida, então, pelo economista entre distintos planos: aproximando o projeto histórico nacionalista da modernização industrial do país com a reflexão e o implante de um novo modelo de desenvolvimento, que aliava o simbólico e a instrumentalidade, a partir da adoção do triângulo composto por cultura, criatividade e desenvolvimento como parâmetro de reflexão e intervenção política. Por esse meio, tornou mútua a tônica heroica das esquerdas marxistas depositada no desenvolvimento das forças produtivas como fator revolucionário na emancipação das classes trabalhadoras e o descrédito no mesmo crédulo revolucionário desenvolvimentista por parte dos autores da teoria crítica da sociedade, ao denunciarem os efeitos deletérios do avanço da modernização técnico-instrumental e da própria sociedade industrial de massas sobre o espírito e à natureza idílica (Lins, 2014:13-19). 
Para melhor entender a repercussão obtida por essas tomadas de posição, cabe situá-las. Tal como sugere Stuart Hall (1997), por volta dos anos de 1970, a questão da cultura adquire importância na estrutura empírica real e na organização das atividades, instituições e relações culturais na sociedade, mais que em qualquer momento histórico particular. Torna-se, também, epistemologicamente decisiva, porque a posição da cultura goza de ascendência, desde então, "em relação às questões de conhecimento e conceitualização, em que a cultura é usada para transformar nossa compreensão, explicação e modelos teóricos do mundo" (Hall, 1997: 01). Ainda de acordo com Hall, nesse mesmo movimento se fragiliza a disjunção marxista entre "super" e "infraestrutura" e, igualmente, dão-se remanejamentos estéticos e de gostos referidos a uma democratização cúmplice do delineamento de mundos múltiplos identitários e de modos e estilos de vida, em escala global. No rastro dessa interseccionalidade, evidencia-se “(...) a ascensão dos novos domínios, instituições e tecnologias associadas às indústrias culturais que transformaram as esferas tradicionais da economia, indústria, sociedade e da cultura em si; a cultura vista como uma força de mudança histórica global; a transformação cultural do quotidiano; a centralidade da cultura na formação das identidades pessoais e sociais" (Hall, 1997: 09). O cenário sociossimbólico decorrente desses cruzamentos esteve vinculado à envergadura adquirida pela mediação de vários processos exercida por um leque amplo de elementos e sua penetrabilidade em conjuntos sempre maiores da população planetária, consubstanciando uma mesma dinâmica histórica em que se define um mercado mundial de bens materiais e intangíveis, sobretudo o plano que abrange estes últimos bens, notadamente aqueles em interação com os esquemas das tecnologias digitais, que absorve capitais que antes se dirigiam a setores clássicos da industrialização - aço, ferro e petróleo.

Até agora temos feito uso da ideia de mediação sem o cuidado de descrevê-la. Entretanto, seu emprego requer precisarmos sua definição frente à exigência de aplicá-la nos desdobramentos da nossa análise acerca das tomadas de posição assinaladas anteriormente em meio a esse cenário social mais abrangente. Em ocasiões diferentes, no intuito mesmo de retomá-la como ferramenta nas suas pesquisas e reflexões, conferindo-lhe papel ativo, Raymond Williams (1979: 98-103) demonstrou as dificuldades de operar com a categoria mediação, a ponto de abandoná-la por definitivo. Para o autor, sempre ocupado com os problemas da teoria e análise cultural, a tendência em assinalar a disjunção entre o simbólico e o material consistia no maior obstáculo nessa recorrência, pois permaneceria inamovível a sentença segundo a qual mediar consiste em estabelecer a ponte entre ambas as dimensões, facultando aos símbolos serem 
reflexos do real histórico. Aqui, o retorno ao tema serve à finalidade de tratar das mediações na dinâmica sócio-histórica de mundialização da ideia de cultura e como, nela, deu-se o advento da narrativa da diversidade cultural. Para isso, tomo de empréstimo, ao modelo do ator-rede latouriano (Latour, 2012: 333-344), a concepção de mediação, mas operando uma triagem, já que descarto o entrosamento mútuo entre as agências de humanos e não humanos. Retenho apenas a proposição de considerar os atos mediativos como agenciamentos que geram efeitos associativos nas redes em que se inscrevem.

Ao recorrermos à ideia de mediação, o que nos importa é observar como a sincronia de tomadas de posição acerca da relação entre simbólico e economia está no anverso de um movimento transnacional de circulação de ideias, respaldado em instituições coordenadas de maneira global, em que os efeitos gerados por atividades intelectuais, consultivas, administrativas e políticas compõem um mesmo tecido de saber e poder, plasmado, entre outras figuras, nas agendas de cultura e desenvolvimento. No entretido das mediações, a imaterialidade desses últimos dispositivos, por sua vez, concretiza-se em múltiplos gestos e falas. Enfim, nesse movimento se tece a rede de interdependências sociofuncionais em meio às quais, entre outros posicionamentos, aqueles de Furtado o fizeram um dos agentes, na medida em que frequentara instâncias como a própria Unesco e, igualmente, estivera no comando de espaços de poder internos ao sistema estatal brasileiro (Barbalho, 2011: 107-128).

Acreditamos que, atentando a trânsitos assim, por um lado, podemos acessar os canais pelos quais a razão do Estado nacional incorpora, certamente, de maneira seletiva, o dueto composto pelas ideias de cultura e desenvolvimento às atuações dos seus representantes no campo cultural doméstico. Por outro, somos instigados a supor os efeitos dessas mediações sobre a razão do ordenamento nacional de poder no instante em que traz implicações a respeito das prioridades das políticas públicas e, desse modo, interfere sobre a funcionalidade mesma da máquina estatal. Parece-nos ser este o ponto nevrálgico quando se dá atenção aos contornos do campo de poder global, pois nos obriga a retomar o debate sobre a ressignificação da função estatal de imputação de sentido legítimo, mas agora com o intuito de observar como, ao gozar do prestígio de ideia-força, entronada como recurso, a cultura ampliada na narrativa da diversidade se manifesta estratégica às questões da coordenação e regulação de populações.

Sob este ponto de vista, nossa aposta é situar a problemática em torno da diversidade cultural no escopo das mediações discursivas e institucionais inscritas em um campo de poder que transcende os estados nacionais, apesar de não os superar lógica e historicamente. Definindo-o como um campo de poder global, 
tomamos de empréstimo a noção de campo de poder ao vocabulário conceitual de Pierre Bourdieu (2011: 103-171). Para este autor, objetivar esse espaço social corresponde ao exercício sociológico de taquigrafar a malha de cruzamentos, simultaneamente, estruturais e funcionais, forjando o espaço de posições de mando e de imposição do sentido legítimo, onde o que está em jogo é a luta pela conversão de diferentes e rivais capitais em capitais simbólicos, isto é, em raridades de sentido, enfim, em prestígio - movimento pelo qual se naturaliza o arbítrio do comando exercido. Em se tratando do campo de poder global, as lutas travadas em meio à sincronia de posições que o integra têm por alvo a definição e afirmação de sentidos dos fatores de regulação e coordenação das complexas relações sociais em escala planetária. Entendemos que os dispositivos geopolíticos do Estado nacional concorrem, ao tempo em que se aliam com as prerrogativas de visibilidade e vendabilidade dos bens culturais no campo de poder global.

Na genealogia executada à busca das fontes em que se assegura o peso conferido à cultura nas sociedades ocidentais, após a década de 1960, autores à maneira de Terry Eagleton (2005: 28) e Michel Denning (2006: 158-178) encontram, para além do credo nas bandeiras redistributivas, a participação de intelectuais integrados à esquerda político-ideológica comprometidos, de um modo ou de outro, com a importância ascendente de movimentos socioculturais, deflagrados entre a população trabalhadora, mas movidos, antes, por lutas por reconhecimento, à maneira de, entre outros, grupos feministas, homossexuais, imigrantes de antigas colônias europeias na Ásia e na África, jovens. Não estamos sugerindo estar, por trás dessa primazia, um complô orquestrado por esquerdistas que, abrindo mão da via revolucionária, tomaram o poder mundial mediante estratégia de guerrilha, apossando-se de cargos e posições em agências do porte da Unesco, de onde propagariam suas ideias. A questão é outra. Identificadas as vinculações de ideias, como as de cultura e desenvolvimento, com formações doutrinário-ideológicas à esquerda, de que modo poderemos entender suas presenças na agenda de órgãos como a Unesco, mas também o Banco Mundial e o BID? E, por outro lado, como encarar a adoção de igual ideário nas agendas que norteiam políticas públicas de diferentes Estados nacionais, tenham governos de direita, ou não?

Em se tratando da formação do campo de poder global, o período seguinte ao fim da Segunda Guerra Mundial, em especial a partir da década de 1960, na composição da malha de cruzamentos funcionais e estruturais faz contracenar, no trânsito e apropriações da ideia de cultura e diversidade cultural, uma rede com suas tantas ramificações rizomáticas composta por instituições internacionais, como a Unesco, organizações não governamentais, órgãos do poder 
público (nacional, estadual e local) e grupos inscritos nos chamados segmentos étnico-populares. Elementos decisivos na instauração de um ambiente comunicacional, em que se dá visibilidade à Carta dos Direitos Humanos e, paulatinamente, conduz a interfaces com movimentos sociais comprometidos com as bandeiras de respeito às diferenças identitárias e culturais (Costa, 2006: 125).

A constelação sócio-histórica, sumariamente descrita, pode ser miniaturizada pela seguinte imagem. 0 número 62 da revista Desafios do Desenvolvimento, editada pelo Instituto de Pesquisa Econômica Aplicada (IPEA), oportunizando a realização em Brasília da $34^{\text {a }}$. Reunião do Comitê do Patrimônio Mundial da Unesco, em 2010, relaciona a diversidade cultural e natural brasileira ao problema do desenvolvimento local e regional no país. Uma das seções do periódico é aberta com uma longa entrevista com Jurema Machado, que, na ocasião, ocupava o cargo de coordenadora de cultura da Unesco no Brasil - atualmente, ela é presidente do IPHAN. Na abertura, consta uma das frases da entrevistada - "No Brasil, as relações entre cultura e desenvolvimento são desafiadoras" - acompanhada da citação, indireta, do texto constitucional em que se garante o direito à cultura no país, desde 1988. Apesar de não existirem maiores afinidades entre a trajetória da arquiteta Jurema Machado e a do economista Celso Furtado, há certa familiaridade no fato de ambos ocuparem posições importantes mediando o relacionamento do governo brasileiro com a Unesco. Ainda que, nessa instituição, ele houvesse exercido funções consultivas e, ela, executivas, as afinidades entre ambos se alarga, observando que as enunciações de um e de outra primam em pôr em conexão o plano dos sentidos e valores com aquele da instrumentalidade, mas tomando por demiurgo a chave dos direitos humanos para sintonizar o valor da igualdade com a ênfase na diferencialidade dos modos de viver, agir e pensar como um traço universal humano.

Portanto, Furtado e Jurema compõem uma mesma linhagem intergeracional de intelectuais, circunstanciada em diferentes estágios, mas cujo trajeto dos seus atos se converteu em séries de mediações que contribuíram para subsidiar a dinâmica da mundialização da cultura, tendo por uma das consequências não programadas o relevo obtido pela narrativa da diversidade aninhada num circuito cosmopolita de interações em níveis graduais de institucionalidade (Mattelart, 2005: 53-153; Nicolau Netto, 2014: 109-166). Quer dizer, os dois participam da sucessão de práticas pela qual se modela, com amparo de larga trama institucional, essa formação discursiva nodal à montagem do espaço simbólico, onde as regras de classificação das "coisas sociais" têm por parâmetro o respeito à dignidade e às tantas formas e feições assumidas pelas experiências humanas (Pitombo, 2011: 89-124). 
Essas vozes da cultura conferem respaldo aos agentes governamentais e dos movimentos socioculturais, no momento mesmo em que evocam o movimento do pós-desenvolvimento com sua tenaz defesa de concepções não lineares de história universal, rechaçam a visão sucessória de estágios atrasados (incipientes e pulverizados) àqueles dos sistemas evoluídos e integrados (modernos). Mostram-se, logo, críticas a projetos modernizadores calcados nas premissas homogeneizantes de desenvolvimento socioeconômico (Rey, 2002; Escobar, 2005: 17-31).

Notamos o quanto a formação discursiva da diversidade cultural penetra, revolve e ressignifica a ideia de desenvolvimento, pressionando-a a integrar o tema das moralidades e, com isso, levando em consideração as proposições identitárias dos muitos coletivos humanos, tributários de memórias, saberes e fazeres singulares e, muitas vezes, irredutíveis entre si (Alves, 2010: 539-560). Algo assim, pelo menos a princípio, se coloca à contramão dos marcos teóricos e doutrinários que nortearam os projetos desenvolvimentistas nacionais, quer liberais capitalistas, quer estatizantes socialistas, pois todos estavam comprometidos em fomentar a potencialidade produtiva dos seus respectivos países pela implantação de parques industriais, sob a promessa de autonomia no tabuleiro do sistema interestatal. ${ }^{10}$

As diferentes programações nacionais respondiam, portanto, à bula de um universalismo histórico para o qual estava em causa saturar todos os recursos humanos e "naturais" com a finalidade de alcançar um mesmo patamar de bem-estar coletivo. Mesmo não abrindo mão da instrumentalidade, o universalismo da diversidade, por sua vez, substituiu a potencialização produtiva pela sustentabilidade includente, estribada na identificação e respeito das condições ecológicas locais, para isto acolhendo a moção favorável à inserção dos tão diferenciados percursos étnico-históricos e sistemas sociossimbólicos mundo afora, reconhecendo saberes e fazeres próprios a esses nichos como insumos à transformação e melhoria das condições de vida dos muitos povos subalternizados (Sachs, 2008: 9-24; 69-110).

\section{Capitais humanos da diversidade: texturas da mundialização?}

Não devemos confundir, porém, a tônica depositada na diversidade com uma suposta recusa da potencialização econômica das diferenças culturais nas agendas de cultura e desenvolvimento. Temos a suspeita de que os mesmos

10 Nesse sentido, não concordamos com proposições de autores como Daniel Mato (2003: 61-72) que restringem à vertente neoliberal a matriz da tônica posta na diversidade e nas identidades étnicas. 
trançados associativos gerados nas mediações descritas fomentaram, por vicissitudes, a interligação entre patrimônios materiais e imateriais e os mercados monetário-financeiros autorregulados. Isto, no tocante às conexões em que os traços diacríticos mais marcantes de um modo de ser e viver - acionados na delimitação de uma identidade local -, já agora diferenciados e sintetizados pela categoria de cultura, tornaram-se fundamentais para que tais patrimônios sejam reconhecidos e absorvidos na economia-mundo capitalista, cujas agências empresariais estão empenhadas em rastrear e agregar diferenças culturais aos catálogos de atrações obedientes aos propósitos de remuneração do capital. Mas que também encontram respaldo nos critérios definidores de políticas públicas executadas por diferentes membros do sistema interestatal, sobretudo aquelas voltadas para guarda e valorização dos patrimônios materiais e intangíveis. ${ }^{11}$

O cruzamento de objetivos do Programa Artesanato Solidário com os do Serviço Brasileiro de Apoio às Micro e Pequenas Empresas (Sebrae) é ilustrativo por permitir constatar o quanto as diretrizes de cultura e desenvolvimento já penetraram a coordenação de agenciamentos no dueto Estado e mercado contemporâneos, no país, de acordo com uma agenda transnacional.

Posto em execução durante a vigência da segunda administração federal Fernando Henrique Cardoso (1998-2002), o Programa Artesanato Solidário esteve embasado nas concepções comparativa, estruturalista e interpretativista do pensamento antropológico. Ou seja, de um lado a cultura é um modo de vida global e, de outro, um sistema de significação e, ainda, uma trama de significados que

11 A experiência artesanal no México, a partir da década de 1960, constitui-se numa espécie de laboratório. Situada na passagem socioestrutural em que a sociedade mexicana ingressava no esquema urbano-industrial, as malhas socioculturais do artesanato passaram a compor outro patamar de integração funcional, cada vez mais com os mercados autorregulados. Dinâmica acentuada durante a presidência da república foi ocupada por Luis Echeverría Álvarez (1970-1976) que, de posse de dividendos provenientes da receita gerada com exploração e exportação petrolífera, notadamente para os Estados Unidos, avançou na interferência estatal de indutor do desenvolvimento econômico e ampliou sua versão de estado previdenciário. Uma das manifestações do entrosamento entre as duas vertentes se deu com a decisão governamental de implantar "El Fundo de Fomento a las Artesanias - FONART -”, em maio de 1974. A missão da FONART, desde então, é resumida nos seguintes termos: "Coordenar, integrar e alinhar as políticas públicas que promovem o desenvolvimento sustentável dos artesanatos mexicanos, de acordo com uma perspectiva multidimensional do fenômeno artesanal, quer dizer, que contempla seu caráter social, econômico, cultural e indígena.” A execução do fundo, no entanto, não pode ser desvinculado do interesse crescente que o setor financeiro estadunidense, naquele momento representado pela Fundação Rockefeller, passa a ter pela produção artesanal mexicana. Adquirindo peças na montagem de um vasto acervo, em sintonia com sua política de aquisição de bens artísticos, a atuação dessa instituição jogara decisivamente à construção do prestígio e do valor econômico da cultura popular artesanal mexicana. Repercutindo assim tanto nos modos de simbolização quanto na ressignificação da autoria que cada vez mais privilegiará a figura do gênio artístico em detrimento do anonimato comunitário (Canclini, 1983: 156-159; Novelo, 2007: 204-293). 
informa e se dilata mediante agenciamentos. Obedientes a essa triangulação, mas definidas como uma ação social "embasada na valorização da cultura e das identidades culturais" (Sampaio, 2003: 45), as atividades do conselho gestor do programa tiveram por alvo, em especial, artesãs e artesãos populares localizados no norte do estado de Minas Gerais e na região nordestina do Brasil, encontrando respaldo no apoio financeiro da Superintendência para o Desenvolvimento da Região Nordeste (Sudene). Embasaram-se, também, nas Recomendações da Unesco para Salvaguarda da Cultura Tradicional e Popular, votada em 1989. Segundo a justificativa para o programa, um e outro apoio integram o objetivo de "revitalizar $\mathrm{o}$ artesanato tradicional como uma manifestação da cultura popular brasileira e, por meio desta revitalização, gerar renda" (Sampaio, 2003: 45). Sendo o artesanato popular apreendido como arte de um modo de vida que se recria intergeracionalmente, de maneira anônima e espontânea, a orientação do Artesanato Solidário era "interferir sem ferir", o que significa evitar a intervenção alienígena, à maneira dos designers; contudo, caberia ajustar o produto artesanal ao "mercado consumidor", com vistas a cumprir a finalidade de gerar rendas para os produtores locais.

Com isso, ao chegar a treze estados da Federação e aglutinar dois mil e quatrocentos oficiais, distribuídos em mais de quinhentos municípios, o esforço de formar recursos humanos hábeis em equalizar a criação coletiva local com padrões da demanda compradora norteou a realização do programa. Além do trabalho conjunto com as prefeituras locais, por meio de convênio, foram oferecidos cursos de gestão e planejamento de empreendimentos por técnicos das representações estaduais do Sebrae, com a finalidade de formar mão de obra autônoma e apta à autossustentabilidade.

A participação do Sebrae veio nos rastros de uma reorientação institucional que, em suas políticas, passava a considerar a cultura. Sem fins lucrativos, essa organização civil de fomento ao empreendedorismo deixava de lado o atendimento a empresas isoladas na medida em que enfatizava o ambiente em que se alocava o empreendimento. Desse modo, a parceria com o Artesanato Solidário contracenou com outras parcerias, principalmente com o Museu Casa do Pontal, no Rio de Janeiro - concretizada no Censo Nacional do Artesanato. Uma vez mais, as prerrogativas da preservação cultural e da valorização identitária foram sintonizadas com o ideário pós-desenvolvimentista em torno da sustentabilidade. Um conjunto de iniciativas foi acionado, entre os quais o de maior visibilidade foi o projeto "Cara Brasileira”. À defesa do projeto, argumentava-se que, posto que os produtos e serviços voltados para o atendimento às necessidades básicas já se encontravam num patamar de superação cada vez maior, o mercado abria-se para bens e atividades de "elevado conteúdo cultural", identificados como 
adequados ao preenchimento das zonas de lazer de potenciais consumidores desejosos por "enriquecimento da consciência e crescimento pessoal", até então ainda pouco explorados em meio às vastas oportunidades proporcionadas pela globalização da economia e das comunicações (Braga, 2003: 55).

Nesse sentido, a proposta do Sebrae seria transformar a diversidade cultural brasileira em fonte de rendimentos. Um passo primeiro diria respeito a "mapear as tipicidades, ícones culturais, símbolos e as referências culturais do local" para que as respectivas comunidades reconhecessem o seu território. Este era um "mecanismo" de fortalecimento regional, afinal incluiria uma "personalidade diferenciada" e "uma visão de futuro" por parte de uma "sociedade local organizada"; na sequência, tratar-se-ia de angariar esforços com a finalidade de tornar esses "territórios competitivos" em espaços "mesorregionais", nacionais e internacionais (Braga, 2003: 57).

Outra vez nos furtamos à tarefa de entrar no mérito das polêmicas que envolveram a execução dos objetivos descritos. No diálogo direto com a perspectiva de Foucault (2008: 297-327), o que nos importa reter do cruzamento descrito são insumos para propor serem as agendas de cultura e desenvolvimento mecanismos de coordenação de relações sociais internos ao regime de governamentalidade do biopoder, em que o conceito de capital humano ocupa posição estratégica. Propagada com base nas ideias surgidas na Escola de Economia da Universidade de Chicago, por volta dos anos de 1960, a vertente de governamentalidade neoliberal estadunidense tem por alvo um âmbito governamental desde sempre comprometido com as prerrogativas liberais. Parte das suas diretrizes (métodos e tipos de programação), a teoria do capital humano decorre da atenção voltada aos temas da criminalidade e da delinquência. Nessa formulação, a economia de mercado embasa o funcionamento e a dinâmica econômica, mas com o propósito de esclarecer fatos sociais que, pelo menos a princípio, não são classificados como econômicos.

A versão de economia política peculiar ao neoliberalismo estadunidense desloca, portanto, o foco do Estado para o conjunto da sociedade. No translado, nota Foucault, as relações sociais, as interações intersubjetivas e os comportamentos dos indivíduos estão atravessados pelo mesmo desígnio, a saber, o mercado constitui a chave de inteligibilidade, tanto ontológica, quanto formal (epistêmico-cognitiva) da vida coletiva e pessoal. A teoria do capital humano focaliza o "humano" como o conjunto de "capacidades, destrezas e aptidões" inerentes aos indivíduos da espécie, mas tais atributos são convertidos em valores de troca a serem internalizados no movimento de remuneração do empreendimento privado. 
A nosso ver, as agendas de cultura e desenvolvimento se manifestam de forma heurística ao entendimento de apropriações diversas do esquema do capital humano, no momento em que vocalizam disposições de fecundar as práticas significantes referidas a saberes e fazeres locais como alavancas sustentáveis de desenvolvimento local. A aplicação das agendas poderá contribuir na metamorfose dessas práticas e, por consequência, seus agentes em recursos a serem modalizados pelas tecnologias discursivas e cibernético-comunicacionais. Enfim, esses dispositivos ocupam estratégica posição na promoção da "conveniência” das culturas (Yudice, 2004). À luz desse diferencial, elas são sempre mais fomentadas em redes institucionais, que aliam governos locais, regionais, nacionais, ao lado de órgãos translaterais e ONGs, com vistas a darem suporte logístico, pedagógico e financeiro a toda sorte de atividades que compareçam como empreendedorismos nativos.

Incorporadas a um só tempo na condição de matéria-prima e de investidor, as agências humanas (suas destrezas e os saberes que portam) são pressionadas a se autorregularem como suficientemente hábeis para se converterem ante os regramentos de instâncias estatais ou não governamentais, mas igualmente em frente aos desígnios dos mercados que se tornam seus novos demandantes, caso obtenham êxito na conversão. Portanto, mediante a sistemática de instâncias que a torna atuante nas relações de forças sociossimbólicas contemporâneas, a intervenção das agendas de cultura e desenvolvimento cobra a autotradução em capitais dos conteúdos diversos da bios humana, quando perfilados em diferenças culturais.

Por certo, causa estranheza anotar a vinculação estreita, senão simbiótica, entre a teoria neoliberal do capital humano e as premissas neodesenvolvimentistas calcadas nos postulados da cumplicidade estabelecida entre diversidade cultural e sustentabilidade. Afinal, os autores dos Departamentos de Economia quanto da Escola de Administração da Universidade de Chicago, Milton Friedman, Theodor Schultz e George Stigler, propuseram a teoria do capital humano no combate aos modelos keynisianos e neokeynesianos. Por sua vez, as frações intelectuais propositoras do neodesenvolvimentismo ocupavam posições à centro-esquerda e à esquerda no espectro político-ideológico. Portanto, não é adequado fazer uma derivação automática da base canônica doutrinária da teoria do capital humano para esclarecer sua inserção nas agendas de cultura e desenvolvimento.

Embora não possamos entrar amiúde, aqui, no cruzado de trajetórias que a possibilitaram, importa assinalar se tratar de uma tradução dos objetivos dessa gramática cognitiva, pois, se estava em jogo, a princípio, potencializar as habilidades e destrezas individuais, segundo a finalidade do empresariamento 
capitalista, ao ser transfigurado, sem perder de vista a dimensão pessoal, o ideário do capital humano incorporou a tônica nos legados intergeracionais de saberes e fazeres já textualizados como tradições culturais. Resultante do concerto desses condicionamentos, emerge um tipo específico de produção de subjetividades que delimita a posição de sujeito da cultura e o faz, exatamente, pela assunção corporal de assegurar a sustentabilidade pessoal, comunitária e da herança sociossimbólica atualizada.

Os resultados das nossas pesquisas deixam ver o quão crucial tem sido a atuação estatal nos rumos tomados pela tradução que incorpora a gramática cognitiva do capital humano nas agendas de cultura e desenvolvimento. De fato, no encadeamento sumariamente descrito neste artigo, define-se outra mediação. A mediação em questão, agora, consiste naquela em que se requisita a funcionalidade dos estados nacionais para o cerne do campo de poder global. Há aspectos para além do fornecimento de meios logísticos e técnicos necessários à conversão dos patrimônios comunitários em bens e serviços aptos a pôr valor de troca. Vejamos de que modo. Redefinidas e articuladas ao emaranhado normativo-institucional das convenções e tratados internacionais, as linhas funcionais de regulação de populações e coordenação social dessas unidades sociais geopolíticas, em especial os arranjos jurídicos e aqueles voltados à área cultural, viabilizam, aos diferentes agenciamentos étnico-históricos, o entrosamento do direito à propriedade intelectual, fundamental ao regime individualista de autoria, com os dispositivos de reconhecimento e visibilidade não somente da singularidade dos bens-expressão culturais comunitários, mas, sobretudo, da sua competência em irem adiante da condição de idiossincrasia local ou regional, mesmo nacional (Farias, 2010: 11-41; Michetti, 2015: 208-210).

Faço outro empréstimo junto a Foucault (2009: 449-487). Para o autor, o Estado nacional centralizado se define da perspectiva da razão estatal cuja governamentalidade que lhe especifica pela administração de populações. Quer dizer, embora ocupando um território legado, direta ou indiretamente, pelo emprego da força bruta e estando essa superfície territorial limitada por outras unidades sociopolíticas congêneres, a dominação da razão estatal se exerce na medida em que desloca o foco das práticas e ferramentas da segurança pública na direção dos estoques heterogêneos entre si de pessoas e grupos, mas que estão distribuídos no interior do seu espaço vital de soberania. O uso da ideia de uma governamentalidade exercida mediante a administração de populações, porém, supõe não a anulação do recurso à força bruta, mas, sim, o aumento intensivo na seletividade desse uso, devido a outras fórmulas. A nosso ver, no mundo contemporâneo, entre as alternativas consta aquela calcada no relevo obtido 
pelo reconhecimento e qualificação de proposições identitárias e autoimagens grupais por áreas da razão estatal.

A metanarrativa da diversidade cultural se situa no interstício das respectivas coordenações exercidas pela díade Estado e mercado. Mais que isso, posiciona a funcionalidade de ambos no campo de poder global. Do ponto de vista do Estado, enquanto efeito de sincronia relativo à regulação de heterogeneidades sociossimbólicas, a coordenação se realiza na continuidade da função estatal de assegurar (ou negar) o status público (nacional) das culturas. Classificação que se dará na concessão de direitos coletivos e no fornecimento de meios à visibilização cosmopolita e à sustentabilidade do bem cultural e de sua comunidade. Já da perspectiva do mercado, a coordenação repercute a identificação estabelecida entre o ser, saber e fazer culturais com o protocolo instrumental e financeiro que normatiza o trânsito do bem simbólico pelos fóruns nos quais o seu valor de diferença irredutível se consagra uma raridade diante das demandas de sentidos genuínos e autênticos. $\mathrm{O}$ recíproco engendramento das coordenadas exercidas por mercado e Estado parece, então, estar indissociável das operações de textualização das diferenças culturais em que contextos geoculturais locais, regionais, nacionais e transnacionais tornam-se permeáveis entre si. Deixam-se ver, nas múltiplas texturas, modulações igualmente mútuas do singular com o mesmo, do simbólico com a materialidade, do cultural com a mercadoria, mas também do comunitário com o cosmopolita, enfim, do extemporâneo com o moderno.

\section{Referências}

ABREU, Regina; CHAGAS, Mário. Memória e patrimônio: ensaios contemporâneos. Rio de Janeiro: DP \& A, 2003.

ALMEIDA, Armando; ALBERNAZ, Maria B.; SIQUEIRA, Maurício (Orgs.). Cultura pela Palavra: Coletiva de artigos, entrevistas e discursos dos ministros da cultura 2003-2004. Rio de Janeiro: Versal, 2013.

ALVES, Elder P. Maia. Diversidade cultural, patrimônio cultural material e cultura popular: a UNESCO e a construção de um universalismo global. Revista Sociedade e Estado, volume 25, n. 03, setembro-dezembro, 2010.

ARRUTI, José Maurício. Mocambo. Antropologia e História do Processo de Formação Quilombola. São Paulo: Anpocs, 2005.

BARBALHO, Alexandre.A Política Cultural segundo Celso Furtado.In: Alexandre Barbalho, Lia Calabre, Paulo Miguez e Renata Rocha (Orgs.): Cultura e Desenvolvimento: perspectivas políticas e econômicas. Salvador: EdUFBA, 2011. 
BHABHA, Homi K. Introduction: narrating the nation. In: Nation and Narration. London e New York: Routledge, 1990.

BOTELHO, Isaura. Romance de Formação. A Funarte e a Política Cultural 1976/199o. Rio de Janeiro, MinC/Ed. Casa de Ruy Barbosa, 2001.

BOURDIEU, Pierre. Da casa do Rei à Razão de Estado: um modelo da gênese do campo burocrático. In: WACQUANT, Loic (org.): O Mistério do Ministério: Pierre Bourdieu e a política Democrática. Rio de Janeiro: Revan, 2005.

Homo Academicus. Florianópolis: UFSC, 2011.

BRAGA, Christiano. A Cultura nas Políticas Públicas e Programas do Sebrae. In: Políticas Culturais para o Desenvolvimento: uma base para a cultura. Brasília: UNESCO Brasil, 2003.

CALABRE, Lia. O conselho Federal de Cultura, 1971-1974. In: Estudos Históricos, Rio de Janeiro, n. 37, janeiro-junho de 2006, p. 81-98.

CANCLINI, Néstor García. As Culturas Populares no Capitalismo. SP: Brasiliense, 1983.

CARVALHO, José Jorge. Culturas populares: contra a pirâmide e por ações afirmativas. Seminário de Políticas Públicas para as Culturas Populares. São Paulo: Pólis, 2006.

CAVALCANTI, Maria Laura V. C. O Rito e o Tempo: ensaios sobre o carnaval. Rio de Janeiro: Civilização Brasileira, 1999.

CAVALCANTI, Maria Laura V. C.; FONSECA, Maria Cecília Londres. Patrimônio Imaterial no Brasil: legislação e políticas estaduais. Brasília: UNESCO, 2008.

COHN, Gabriel. A Concepção Oficial da Política Cultural nos Anos 70. In: MICELI, SÉRGIO (org.): Estado e Cultura no Brasil. São Paulo: DIFEL, 1984.

COSTA, Sérgio. Dois Atlânticos: teoria social, antirracismo cosmopolitismo. Belo Horizonte: UFMG, 2006.

DENNING, Michael. A Cultura na Era dos Três Mundos. São Paulo: Francis, 2006.

DURAND, José Carlos. A cultura como objeto de política pública. São Paulo em Perspectiva, vol. 15 n. 2, São Paulo Apr./June 2001.

EAGLETON, Terry. Depois da Teoria: um olhar sobre os estudos culturais e o pós-modernismo. RJ: Civilização Brasileira, 2005.

ELIAS, Norbert. Introdução à Sociologia. Lisboa: Edições 70, 2008.

ESCOBAR, Arturo. El 'Postdesarrollo' como Concepto y Práctica Social. In: Daniel Mato (coord.): Políticas de economía, ambiente y sociedad en tiempos de globalización. Caracas: Facultad de Ciencias Económicas y Sociales, Universidad Central de Venezuela, 2005, p. 17-31.

EVANGELISTA, Ely G. dos. A UNESCO e o Mundo da Cultura. Brasília (DF): UNESCO - Goiânia: UFG, 2003. 
FALCÃO, Joaquim Arruda. Política Cultural e Democracia: A Preservação do Patrimônio Histórico e Artístico Nacional. In: MICELI, Sergio (org.): Estado e Cultura no Brasil. São Paulo: DIFEL, 1984.

FARIAS, Edson. O Que Pode a Triangulação entre Dinheiro, Expressões Culturais e Esfera Pública nos Dizer sobre Diversidade e Universalidade? In: CASTRO, Ana Lúcia (Org.): Cultura Contemporânea, Identidades e Sociabilidades: olhares sobre corpo, mídia e novas tecnologias. São Paulo: Cultura Acadêmica, 2010.

FONSECA, Maria Cecília Londres. Referências Culturais: base para novas políticas de patrimônio In: Inventário Nacional de Referências Culturais - Manual de Aplicação. Brasília: IPHAN, 2000.

FOUCAULT, Michel. Segurança, Território, População. São Paulo: Martins Fontes, 2009. . Nascimento da Biopolítica. São Paulo: Martins Fontes, 2008.

FURTADO, Celso. Ensaios sobre Cultura e o Ministério da Cultura. Rio de Janeiro: Contraponto - Centro Documental Celso Furtado, 2012 (Arquivos Celso Furtado). GONÇALVES, José Reginaldo S. A Retórica da Perda: discursos do patrimônio cultural no Brasil. Rio de Janeiro: UFRJ, 1996.

HALL, Stuart. A centralidade da cultura: notas sobre as revoluções culturais do nosso tempo. Educação \& realidade 22.2 (1997): 15-46.

. Da Diáspora: identidades e mediações culturais. Organização: Liv Sovik. Belo Horizonte: UFMG; Brasília: UNESCO, 2003.

IPHAN. Coletânea de leis sobre preservação do Patrimônio. Rio de Janeiro: IPHAN, 2006. . Os sambas, as rodas, os bumbas, os meus e os bois: a trajetória da salvaguarda do patrimônio cultural imaterial no Brasil. Brasília: IPHAN/DPI, 2006a.

LATOUR, Bruno. Reagregando o Social: uma introdução à teoria do ator-rede. Salvador: EdUFBA; Bauru: EDUSC, 2012.

LINS, Artur André. Cultura, Criatividade e Desenvolvimento: a contribuição de Celso Furtado. Programa de Iniciação Científica - Relatório Final, ProIC/UnB-CNPq, 2013/2014.

KUPPER, Adam. Cultura: a visão dos antropólogos. Bauru: EDUSC, 2002.

MACHADO, Mario Brockmann. Notas sobre Política Cultural no Brasil. In: MICELI, SERGIO (org.): Estado e Cultura no Brasil. São Paulo: DIFEL, 1984.

MALLORQUIN, Carlos. Repensando la Noción de 'Heterogeneidad' en la Concepción Estructuralista Latinoamericana. In: CVARRUBIAS, H. M.; ESQUIVEL, R. S.; LAU, E. Z. (coord.): Visiones del Desarrollo. Universidad Autónoma de Zacateca, 2012.

MARQUÊS, Lucas Mendonça. Agendas para Atuação de Órgãos Públicos e Cultura Popular. Programa de Iniciação Científica - Relatório Final, ProIC/UnB-CNPq, $2011 / 2012$. 
MATO, Daniel. Actores Sociales Transnacionales, Organizaciones Indígenas, Antropólogos

y Otros Profesionales en la Producción de Representaciones de 'cultura y Desarrollo'. In: Daniel Mato (Org.): Políticas de Identidades y Diferencias Sociales en Tiempos de Globalización. Caracas: FACES, 2003.

MATTELART, Armand. Diversidade Cultural e Mundialização. São Paulo: Parábola, 2005. MICELI, Sérgio. O Processo de "Construção Institucional” na Área Cultural Federal (Anos 70) In: MICELI, Sergio (org.): Estado e Cultura no Brasil. São Paulo: DIFEL, 1984b.

MICHETTI, Miqueli. Moda Brasileira e Mundialização. São Paulo: Annablume/ FAPESP, 2015.

NICOLAU NETTO, Michel. O Discurso da Diversidade e a World Music. São Paulo: Annablume/ FAPESP, 2014.

NOGUEIRA, Antônio Gilberto Ramos. Inventário e patrimônio cultural no Brasil. História, 2007.

NOVELO, Victoria. Artesanos, Artesanías y Arte Popular de México: una historia ilustrada. México (DF): Consejo Nacional para Cultura y Artes, 2007.

OLIVEIRA, Almir Féliz Batista de. O IPHAN e o seu papel na construção/ampliação do conceito de patrimônio histórico/cultural no Brasil. Cadernos do CEOM, ano 21, n. $29,2008$.

OLIVEIRA, Ana Guita. Diversidade Cultural como Categoria Organizadora de Políticas Públicas In: CARVALHO, Marcus Vinícius; GUSMÃO, Rita e TEIXEIRA, João Gabriel (Orgs): Patrimônio imaterial, performance cultural e (re)tradicionalização. Brasília (DF): TRANSE/UnB, 2004.

OLIVEN, Ruben George. Patrimônio intangível: considerações iniciais. In: ABREU, Regina e CHAGAS, Mário (Orgs.): Memória e Patrimônio: ensaios contemporâneos. Rio de Janeiro: Lamparina, 2009.

OLIVEN, Ruben George. Rio Grande do Sul: um estado de fronteira. Revista Eletrônica CELPCYRO, 2002.

OLIVEN, Ruben George. A Relação Estado e Cultura no Brasil: cortes ou continuidade? In: MICELI, Sergio (org.): Estado e Cultura no Brasil. São Paulo DIFEL, 1984.

ORTIZ, Renato. Universalismo e Diversidade. São Paulo: Boitempo, 2015. . Cultura Brasileira e Identidade Nacional. São Paulo: Brasiliense, 1984.

PITOMBO, Mariella. A diferença como Um Bem Universal: a noção de diversidade cultural no discurso da UNESCO. In: ALVES, Elder P. Maia (Org.): Polítics Culturais para as Culturas Populares no Brasil Contemporâneo. Macéio: Edufal, 2011.

REIS, Paula Félix. Política Cultural no Brasil: análise do sistema e do Plano Nacional de Cultura. In: Alexandre Barbalho, Lia Calabre, Paulo Miguez e Renata Rocha (Orgs.): Cultura e Desenvolvimento: perspectivas políticas e econômicas. Salvador: EdUFBA, 2011. 
REY, Germán. Cultura y Desarrollo Humano: Unas relaciones que se trasladan. Pensar Hiberoamérica - Revista de Cultura, n. o, febrero de 2002.

RUBIM, Antônio Albino C. Políticas Culturais do Governo Lula/Gil: desafios e enfrentamentos In: RUBIM, Antônio Albino C. \& BAYARDO, Rubens (Orgs.): Políticas Culturais na Ibero-América. Salvador: Edufba, 2008.

SACHS, Ignacy. Desenvolvimento: includente, sustentável sustentado. Rio de Janeiro: Garamond, 2008.

SAMPAIO, Helena. A experiência do Artesanato Solidário. In: Políticas Culturais para o Desenvolvimento: uma base para a cultura. Brasília: UNESCO Brasil, 2003.

SANT’ANNA, Márcia. A preservação de sítios históricos no Brasil (1937-1990), 1990. Disponível em: <http://www2.archi.fr/SIRCHAL/seminair/SirchalQ/marcia.htm>. Acesso em: 23 abr. 2017.

SANTIAGO, Silviano. O Intelectual Modernista Revisitado. Nas Malhas da Letra. São PAULO, Companhia das Letras. 1989.

VELHO, Gilberto. Patrimônio, negociação e conflito. Mana, abril, 2006.

VIANNA, Letícia Costa R. Pluralidade Cultural e Identidade Nacional: experiências recentes de politicas no Brasil. In: CARVALHO, Marcus Vinícius; GUSMÃO, Rita e TADDEI NETO, Pedro. Preservação Sustentada de Sítios Históricos: a experiência do Programa Monumenta. In: Políticas Culturais para o Desenvolvimento: uma base para a cultura. Brasília: UNESCO Brasil, 2003.

YUDICE, George. A Conveniência da Cultura - Usos da Cultura na Era Global. Belo Horizonte: UFMG, 2004.

WERTHEIN, Jorge. A Construção \& Identidades: as ideias da UNESCO no Brasil. Brasília: UNESCO, 2002.

WILLIAMS, Raymond. Marxismo e Literatura. Rio de Janeiro: Zahar Editores, 1979.

Recebido em 11/11/2016

Aprovado em 19/12/2016

\section{Como citar este artigo:}

FARIAS, Edson; LINS, Artur André. Diversidade, Agendas de Cultura e Desenvolvimento e Mediações no Campo de Poder Global. Contemporânea - Revista de Sociologia da UFSCar, v. 7, n. 1, jan.- jun. 2017, pp. 63-90. 